\title{
Morphometric Analysis and Tagging Experiments for Stock Discrimination of Cresthead Flounder Pleuronectes Schrenki around Hokkaido
}

\author{
Shin-ichi Yokoyama \\ Hokkaido Institute of Mariculture, Shikabe, Hokkaido 041-1404, Japan \\ (Received September 2, 1997)
}

\begin{abstract}
In order to determine the stock structure of the cresthead flounder Pleuronectes schrenki around Hokkaido, stocks were separated by morphometric characters and tagging experiments. The twenty morphometric characters of cresthead flounder (male: 543 , female: 464 ) collected from ten locations between October 1993 and November 1994 were measured. Measurements were standardized to all male and female mean body length. When canonical discriminant analysis was applied to eleven morphometric characters which were selected by stepwise discriminant analysis, the cresthead flounder stocks were classified into two groups, i.e. the sea group and the lake group.

Tagged cresthead flounders of 1,011 individuals were released from Abashiri Bay and the Sea of Okhotsk off Saroma Lake between 1993 and 1995. A total of 40 recaptures of individuals released off Saroma Lake were caught in the tagging area between April 1993 and September 1995. A total of 43 recaptures of those released in Abashiri Bay were caught in the northwestward region from Abashiri Bay and the Japan Sea coast of Hokkaido between April 1995 and December 1996. Tag recaptures were compared with the results of the canonical discriminant analysis.
\end{abstract}

Key words: Pleuronectes schrenki, morphometric analysis, tagging experiment, stock discrimination

The cresthead flounder Pleuronectes schrenki is usually distributed in the coastal regions of Kuril Islands, Sakhalin, and Hokkaido at the depth of less than $100 \mathrm{~m}$. It is also distributed in Saroma Lake and Notoro Lake of brackish water at the depth of less than $20 \mathrm{~m}$ along the Okhotsk Sea coast of Hokkaido. These lakes have one or two artificial outlets. A stock discrimination of the cresthead flounder which is distributed in a coastal region of Hokkaido was mainly examined based on tagging experiments for effective management of this resource. ${ }^{1,2)}$ Morita and Ohara ${ }^{1)}$ concluded that there were four stocks in the Sea of Okhotsk and the Sea of Japan: Notoro Lake stock, Saroma Lake stock, northern Japan Sea-Okhotsk Sea stock, and Shakotan stock. Moreover, they ${ }^{1}$ also revealed that the juvenile and young fish of the northern Japan Sea-Okhotsk Sea stock grew in the Sea of Okhotsk, then adult fish spawned in the Sea of Japan. In order to clarify the distribution of each stock along the Okhotsk Sea coast of Hokkaido, Yokoyama and Shimoyama ${ }^{2)}$ summarized the tagging experiments conducted so far. According to their work, although many recaptures of the cresthead flounders released from the Okhotsk Sea coast between Abashiri and Yubetsu are caught in the Sea of Japan, the tagged fish in Saroma Lake and Notoro Lake frequently remain in the released area. It is also suggested that the distribution of the northern Japan Sea-Okhotsk Sea stock, Saroma Lake stock, and Notoro Lake stock overlaps in coastal regions between Abashiri and Yubetsu. Therefore, other techniques to distinguish them are required.

Morphometric and meristic studies have provided results useful for identifying marine fish stocks. ${ }^{3}$ (shida ${ }^{4)}$ identified local variations of cresthead flounders among five locations around Hokkaido from meristic characters. In Ishida's study, ${ }^{4}$ the Okhotsk Sea coast of Hokkaido and Saroma Lake were not included in sampling locations. The purpose of the present study is to discriminate stocks of cresthead flounder using morphometric characters and tag recapture data in the Okhotsk Sea coast and the Japan Sea coast of Hokkaido.

\section{Materials and Methods}

\section{Morphometric Analysis}

To measure morphometric characters samples were obtained from commercial fisheries in ten locations between October 1993 and November 1994 (Fig. 1): Abashiri (Abashiri Bay), Ubaranai (Notoro Lake), Tokoro (the Sea of Okhotsk off Saroma Lake and Saroma Lake of Tokoro side), Yubetsu (the Sea of Okhotsk off Saroma Lake and Saroma Lake of Yubetsu side), Monbetsu, Esashi, Rumoi, and Aonae. Body size and fishing season could not be unified and differed by the fishery ground, mesh size, fishing gear, and sampling period. Samples were frozen as soon as possible and stored for further processing in the laboratory. The fish were sexed and otoliths were removed for age determination. ${ }^{5)}$ The twenty morphometric characters including a set of thirteen truss network measurements between seven landmarks are shown in Fig. 2. Truss network measurements were obtained by laying the fish on a water-resistant film and inserting pins in the film at landmarks. Strauss and Bond ${ }^{6)}$ suggest that the character set may need to consist both of truss measurements and an auxiliary set of conventional measurements. In the present study the morphometric character set combined the truss network measurements with the conventional measure- 


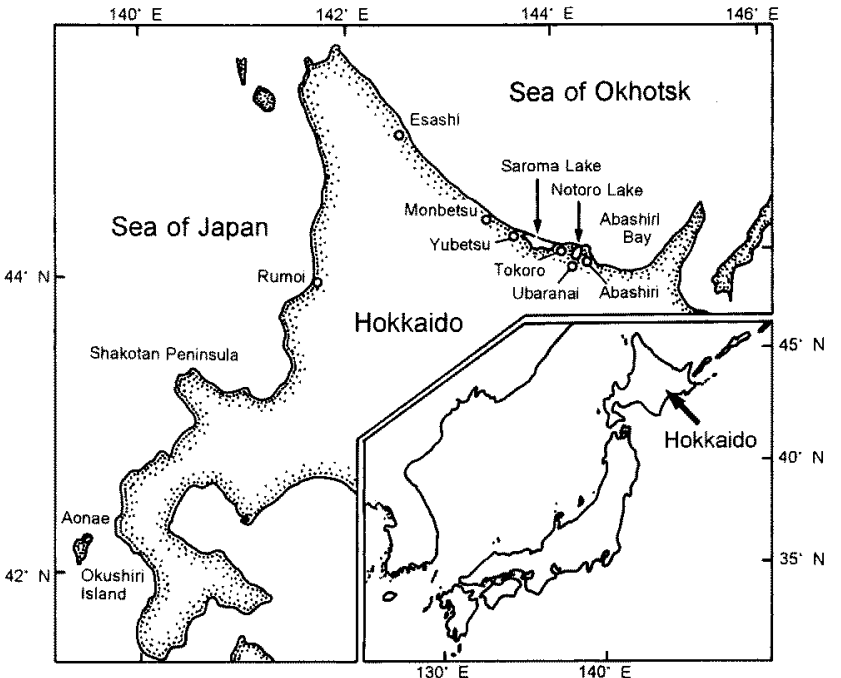

Fig. 1. Sampling locations in the Okhotsk Sea coast and the Japan Sea coast of Hokkaido.

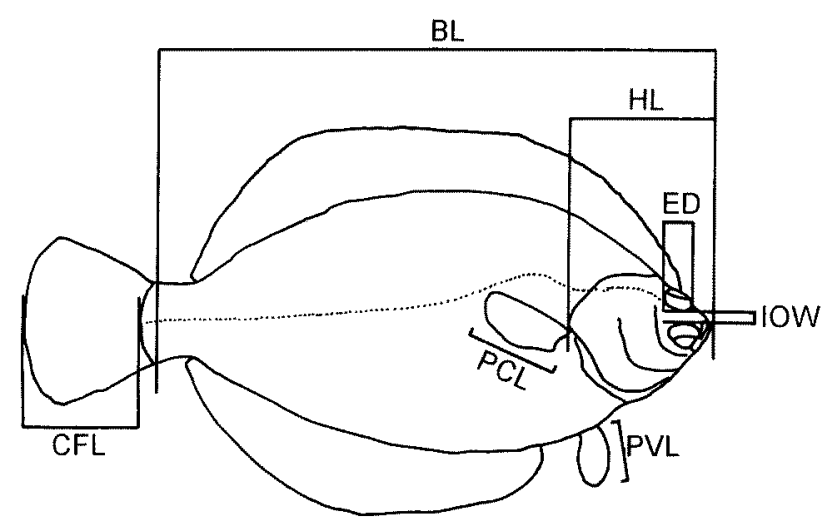

Conventional measurements

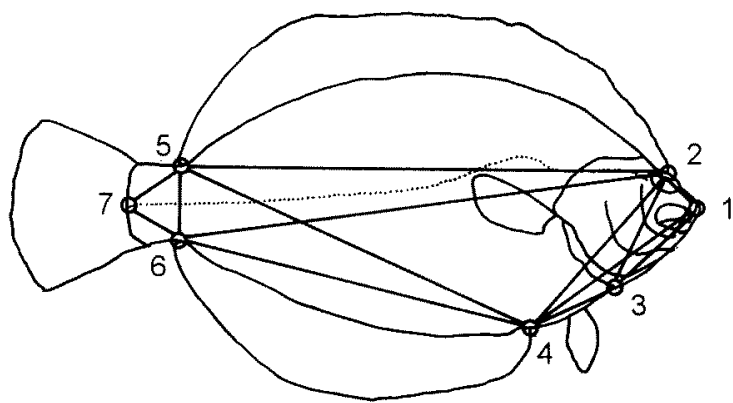

Truss network measurements

Fig. 2. Locations of conventional measurements and thirteen truss network measurements between seven landmarks (open circles).

$\mathrm{BL}$, body length; HL, head length; $\mathrm{ED}$, eye diameter; IOW, interorbital width; PCL, pectoral fin length; PVL, pelvic fin length; $\mathrm{CFL}$, caudal fin length.

ments such as body length (BL: length between tip of snout and margin of hypural bone), head length (HL), eye diameter (ED), interorbital width (IOW), pectoral fin length (PCL), pelvic fin length (PVL), and caudal fin length (CFL). Body depth was also measured, but was discarded because there was no landmark between the base of the dorsal and pelvic fins on flounder and it was difficult to measure accurately. All distances were measured on the eye side with calipers in $0.1 \mathrm{~mm}$ intervals.

For the case in which differences in growth are considered, only fish with the same age are used. ${ }^{7,8)}$ The age compositions of catches in the Sea of Okhotsk differ from those in the northern Sea of Japan.9 ${ }^{9)}$ Therefore, customary transformation of data was used to correct for length effects in stock discrimination. All the distant measurements were log-transformed, and were standardized to all male and female mean body length to minimize variations due to allometric growth and differences in mean size. Standardization was obtained using the formula:

$$
C V=O V-S(B L-m B L)
$$

where $C V$ is the corrected variable, $O V$ is the original variable, $m B L$ is the mean body length of all male and female fish, and $S$ is the slope of the regression of $O V$ against $B L$. A one-way analysis of variance (ANOVA) was applied to the corrected variables to test for sample differences. The canonical discriminant analysis was applied to morphometric characters. The stepwise linear discriminant function was used to help in choosing the correct subset of variables to be used in canonical discriminant analysis. These were performed using the programs of Seto/B. ${ }^{10)}$

\section{Tagging Experiments}

Between April and May in each of 1993 and 1994 cresthead flounders for tagging experiments were caught with commercial flatfish gillnets in the Sea of Okhotsk off Saroma Lake. The body lengths of healthy individuals were recorded and anchor tags were attached at the insertion of the dorsal fin using a tagging gun. A total of $378 \mathrm{in}$ dividuals was released in the same area as catching. On 2 December 1994 and 6 November 1995 cresthead flounders were also released in Abashiri Bay. The fish for tagging were collected by commercial flatfish gillnets. Individuals without apparent damage were held in a tank with running sea water in a laboratory for five to eleven days. After the body length of each fish was recorded, a total of 633 individuals was tagged and released in the same manner as above.

\section{Results}

Differences between Samples Based on Morphometrics

Tables 1 and 2 show age compositions and mean body lengths of cresthead flounder at each sampled location. Although the samples in Ubaranai, Saroma T (Saroma Lake of Tokoro side), and Saroma Y (Saroma Lake of Yubetsu side) were older for both sexes than in the Sea of Okhotsk between Abashiri and Esashi, mean body lengths were smaller. In the samples of Notoro Lake, Saroma Lake, and the Sea of Japan the males of age seven to ten years and the females of age eight to ten years were included but not in the Sea of Okhotsk.

The ANOVA on the adjusted morphometric measurements gave significant differences among samples for both sexes at the $1 \%$ level for twenty measurements. The performance of a particular subset of variables was evaluated on the basis of the value of Wilks' lambda in a stepwise linear discriminant function. The lowest value of Wilks' lambda was represented in the case of eleven variables (male: 
Table 1. Percentage of cresthead flounder in age classes of sampled site

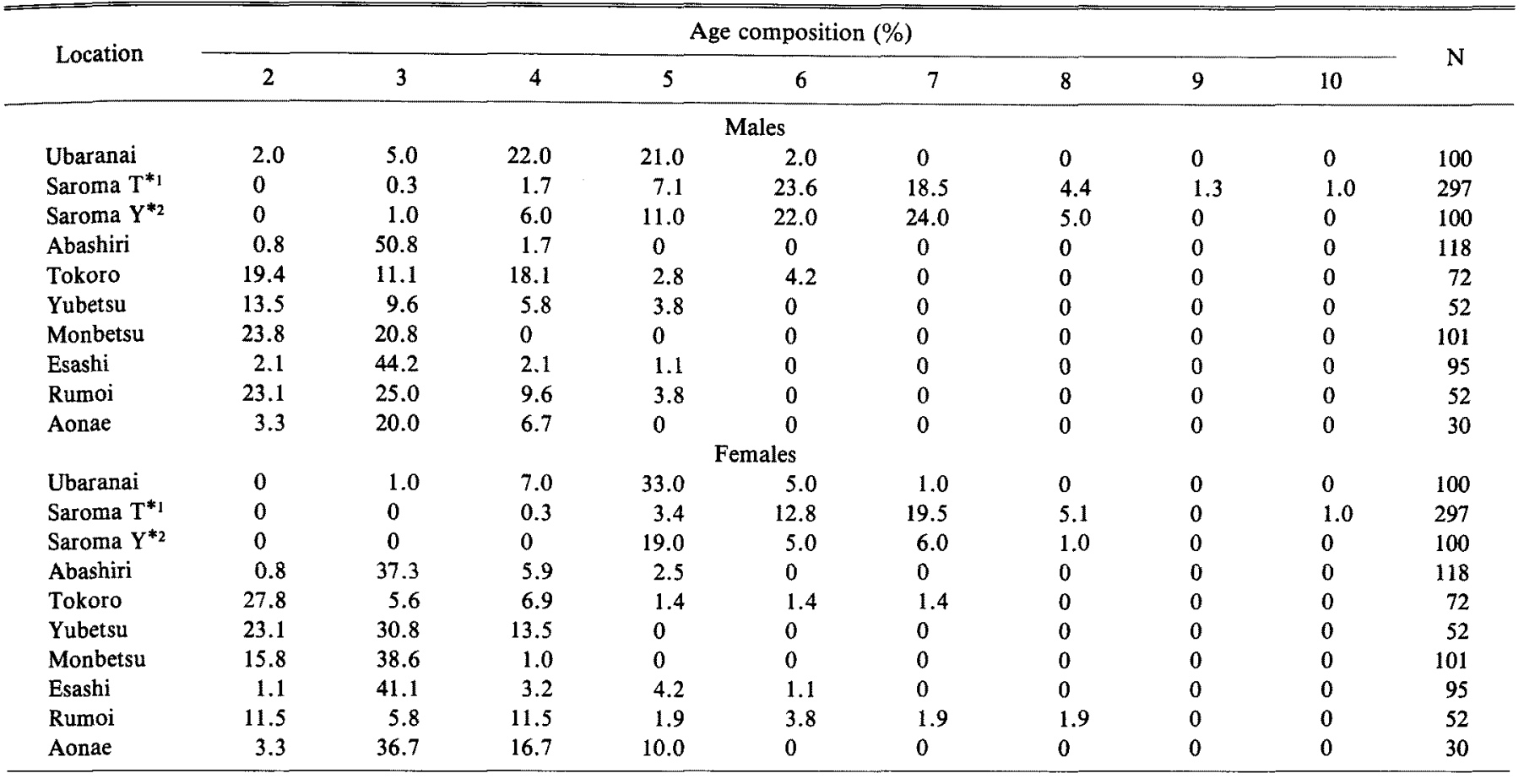

*1 Saroma Lake of Tokoro side.

*2 Saroma Lake of Yubetsu side.

Table 2. Descriptive statistics of body length for males and females cresthead flounder by sampled sites

\begin{tabular}{|c|c|c|c|c|c|c|c|c|c|c|}
\hline \multirow{2}{*}{ Location } & \multicolumn{5}{|c|}{ Males } & \multicolumn{5}{|c|}{ Females } \\
\hline & $N$ & $\begin{array}{l}\text { Mean } \\
(\mathrm{mm})\end{array}$ & $\mathrm{SD}$ & $\underset{(\mathrm{mm})}{\operatorname{Min}}$ & $\underset{(\mathrm{max})}{\operatorname{Max}}$ & $N$ & $\begin{array}{l}\text { Mean } \\
(\mathrm{mm})\end{array}$ & $\mathrm{SD}$ & $\begin{array}{l}\text { Min. } \\
(\mathrm{mm})\end{array}$ & $\begin{array}{l}\text { Max. } \\
(\mathrm{mm})\end{array}$ \\
\hline Ubaranai & 66 & 175.3 & 17.4 & 119.3 & 224.9 & 53 & 199.8 & 23.8 & 160.0 & 287.7 \\
\hline Saroma $T^{*}$ & 172 & 175.2 & 15.1 & 143.0 & 249.1 & 124 & 193.7 & 16.8 & 125.0 & 252.1 \\
\hline Saroma $\mathrm{Y}^{*}$ & 89 & 173.6 & 10.9 & 141.0 & 187.8 & 68 & 176.0 & 9.7 & 154.0 & 199.3 \\
\hline Abashiri & 63 & 238.2 & 14.8 & 201.3 & 275.0 & 55 & 249.2 & 19.1 & 201.1 & 282.2 \\
\hline Yubetsu & 17 & 194.1 & 12.7 & 175.1 & 214.8 & 35 & 210.0 & 20.8 & 156.5 & 257.0 \\
\hline Monbetsu & 45 & 205.1 & 13.2 & 184.3 & 232.2 & 56 & 209.2 & 12.6 & 187.7 & 238.5 \\
\hline Esashi & 47 & 227.3 & 18.8 & 171.0 & 267.4 & 48 & 242.9 & 18.2 & 195.3 & 285.0 \\
\hline Rumoi & 32 & 232.6 & 31.5 & 184.9 & 307.0 & 20 & 279.1 & 61.2 & 183.8 & 363.0 \\
\hline Aonae & 10 & 245.5 & 28.3 & 203.5 & 294.0 & 20 & 261.7 & 24.2 & 231.1 & 324.0 \\
\hline
\end{tabular}

* See the footnote of Table 1.

0.046 , female: 0.025 ), and was significant at the $1 \%$ level for both sexes. The reclassification matrix using eleven characters in a discriminant analysis showed correct classification ranging from $56.3 \%$ to $83.8 \%$ in males and from $48.1 \%$ to $100 \%$ in females (Table 3 ). The misdiscriminations mostly occurred between lake samples (Ubaranai, Saroma $T$, and Saroma $Y$ ) and between sea samples (Abashiri, Tokoro, Yubetsu, Monbetsu, Esashi, Rumoi, and Aonae).

Plots of the first two canonical axes for males and females, illustrating the degree of overlap of the ten samples, are represented in Fig. 3. The two axes accounted for $77.4 \%$ and $50.5 \%$ of the total dispersion in males and $84.3 \%$ and $51.6 \%$ in females. Clear separation of lake samples and sea samples was observed along the first canonical axis for both sexes. The Abashiri sample in males and the Saroma Y sample in females showed little overlap with the other samples along the second canonical axis. The head dimension such as HL, ED, 1-2, 1-3, and 1-4 contributed most strongly to the first canonical variable for both sexes (Table 4).

\section{Coastal Movements of Tagged Fish}

The mean body length of the fish released from Abashiri Bay was significantly larger than those released from the Sea of Okhotsk off Saroma Lake $(P<0.01)$ (Table 5). The body length range of the fish released from Abashiri Bay was narrower than those from the Sea of Okhotsk off Saroma Lake.

Forty of 378 cresthead flounders released from the Sea of Okhotsk off Saroma Lake in 1993 and 1994 were recaptured between April 1993 and September 1995 (Table 5). Forty three of 633 fish released from Abashiri Bay in 1994 and 1995 were recaptured between April 1995 and Decem- 
Table 3. Results of reclassification of individual fish into regional groups based on discriminant analysis

\begin{tabular}{|c|c|c|c|c|c|c|c|c|c|c|c|}
\hline \multirow{2}{*}{ Origin } & \multirow{2}{*}{$N$} & \multicolumn{10}{|c|}{ Reclassification (\%) } \\
\hline & & Ubaranai & Saroma $T^{*}$ & Saroma $Y^{*}$ & Abashiri & Tokoro & Yubetsu & Monbetsu & Esashi & Rumoi & Aonae \\
\hline \multicolumn{12}{|c|}{ Males } \\
\hline Ubaranai & 52 & 83.0 & 5.7 & 3.8 & 1.9 & 3.8 & 0 & 1.9 & 0 & 0 & 0 \\
\hline Saroma $\mathrm{T}^{*}$ & 171 & 7.2 & 81.6 & 7.2 & 0 & 0.5 & 1.4 & 1.4 & 0.5 & 0 & 0 \\
\hline Saroma $\mathrm{Y}^{*}$ & 68 & 1.5 & 10.3 & 83.8 & 0 & 0 & 4.4 & 0 & 0 & 0 & 0 \\
\hline Abashiri & 62 & 0 & 0 & 0 & 83.1 & 4.6 & 3.1 & 4.6 & 4.6 & 0 & 0 \\
\hline Tokoro & 39 & 0 & 0 & 2.6 & 0 & 61.5 & 7.7 & 10.3 & 2.6 & 12.8 & 2.6 \\
\hline Yubetsu & 17 & 0 & 5.9 & 0 & 0 & 17.6 & 70.6 & 0 & 0 & 5.9 & 0 \\
\hline Monbetsu & 45 & 0 & 0 & 0 & 0 & 11.1 & 2.2 & 77.8 & 4.4 & 4.4 & 0 \\
\hline Esashi & 47 & 0 & 0 & 0 & 2.1 & 0 & 8.5 & 6.4 & 76.6 & 2.1 & 4.3 \\
\hline Rumoi & 32 & 0 & 0 & 3.1 & 0 & 12.5 & 15.6 & 3.1 & 0 & 56.3 & 9.4 \\
\hline Aonae & 10 & 0 & 0 & 0 & 0 & 10.0 & 0 & 0 & 0 & 10.0 & 80.0 \\
\hline \multicolumn{12}{|c|}{ Females } \\
\hline Ubaranai & 47 & 78.7 & 14.9 & 0 & 0 & 2.1 & 2.1 & 0 & 0 & 0 & 2.1 \\
\hline Saroma $\mathrm{Y}^{*}$ & 31 & 0 & 0 & 100,0 & 0 & 0 & 0 & 0 & 0 & 0 & 0 \\
\hline Abashiri & 54 & 3.7 & 0 & 0 & 48.1 & 1.9 & 3.7 & 20.4 & 9.3 & 3.7 & 9.3 \\
\hline Tokoro & 31 & 0 & 0 & 0 & 3.2 & 61.3 & 16.1 & 3.2 & 0 & 12.9 & 3.2 \\
\hline Yubetsu & 35 & 2.9 & 0 & 0 & 2.9 & 11.4 & 60.0 & 5.7 & 5.7 & 11.4 & 0 \\
\hline Monbetsu & 56 & 0 & 1.7 & 0 & 5.0 & 8.3 & 1.7 & 80.0 & 1.7 & 0 & 1.7 \\
\hline Esashi & 47 & 0 & 0 & 4.3 & 8.5 & 0 & 4.3 & 6.4 & 66.0 & 4.3 & 6.4 \\
\hline Rumoi & 18 & 0 & 0 & 5.0 & 0 & 20.0 & 5.0 & 5.0 & 5.0 & 55.0 & 5.0 \\
\hline Aonae & 20 & 0 & 0 & 0 & 5.0 & 0 & 0 & 0 & 5.0 & 5.0 & 85.0 \\
\hline
\end{tabular}

* See the footnote of Table 1.
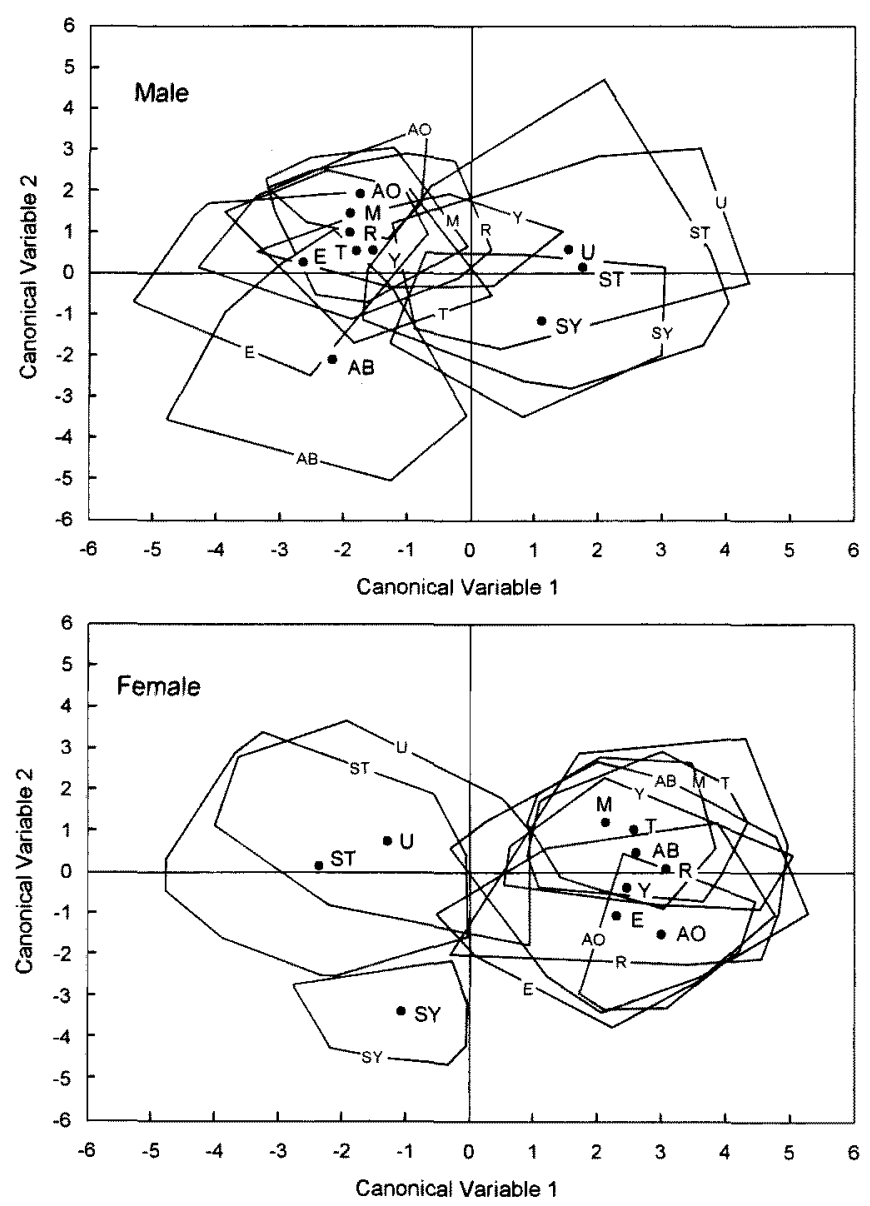

Fig. 3. Centroids (solid circles) of canonical variables 1 and 2 based on eleven adjusted morphometric characters for the ten samples of male and female cresthead flounder.

Contours enclose all cases in each location. Letters show sampling locations: U, Ubaranai; ST, Saroma Lake of Tokoro side; SY, Saroma Lake of Yubetsu side; AB, Abashiri; T, Tokoro; Y, Yubetsu; M, Monbetsu; E, Esashi; R, Rumoi; AO, Aonae.
Table 4. Total canonical structure in the case of eleven variables

\begin{tabular}{|c|c|c|c|c|c|}
\hline \multicolumn{3}{|c|}{ Males } & \multicolumn{3}{|c|}{ Females } \\
\hline \multirow{2}{*}{ Character } & \multicolumn{2}{|c|}{ Canonical variable } & \multirow{2}{*}{ Character } & \multicolumn{2}{|c|}{ Canonical variable } \\
\hline & 1 & 2 & & 1 & 2 \\
\hline $\mathrm{HL}$ & 0.84 & -0.02 & $\mathrm{HL}$ & -0.92 & -0.20 \\
\hline ED & 0.60 & 0.44 & $\mathrm{ED}$ & -0.72 & -0.03 \\
\hline IOW & 0.54 & -0.23 & IOW & -0.60 & 0.51 \\
\hline CFL & 0.54 & 0.10 & CFL & -0.51 & -0.19 \\
\hline $1-2$ & 0.64 & 0.03 & $1-2$ & -0.79 & 0.33 \\
\hline $1-3$ & 0.68 & -0.49 & $2-3$ & -0.58 & -0.12 \\
\hline $1-4$ & 0.66 & -0.06 & $2-5$ & 0.76 & -0.11 \\
\hline $2-6$ & -0.60 & 0.41 & $3-4$ & -0.36 & 0.18 \\
\hline $4-5$ & -0.54 & -0.38 & $4-5$ & 0.68 & 0.44 \\
\hline 5.6 & -0.60 & -0.30 & $5-6$ & 0.70 & 0.11 \\
\hline $6-7$ & -0.0005 & 0.00009 & $6-7$ & 0.17 & -0.44 \\
\hline
\end{tabular}

Acronyms refer to morphometric characters as in Fig. 2.

ber 1996. Recaptures of fish released from both areas concentrated between April and June, and were rare between July and December. There was no recapture between January and March because the drift ice of the Sea of Okhotsk and the frozen surface of Saroma Lake and Notoro Lake prevented fishing. Of the fish released from the Sea of Okhotsk off Saroma Lake, recaptures hardly moved from the released points (Fig. 4). Of the fish released from Abashiri Bay, $4.9 \%$ were recaptured in the northwestward regions apart from Abashiri Bay, and one recapture was made in the Sea of Japan (Fig. 5).

\section{Discussion}

The results of both approaches suggested the existence of two groups of cresthead flounder in the Okhotsk Sea coast and the Japan Sea coast of Hokkaido: a lake group 
Table 5. Released and recaptured data for tagged cresthead flounder

\begin{tabular}{|c|c|c|c|c|c|c|c|c|}
\hline \multicolumn{6}{|c|}{ Release } & \multicolumn{3}{|c|}{ Number of Recaptures } \\
\hline \multirow{2}{*}{ Date } & \multirow{2}{*}{ Area } & \multirow{2}{*}{$\begin{array}{c}\text { Total } \\
\text { number }\end{array}$} & \multicolumn{3}{|c|}{ Body length (mm) } & \multirow{2}{*}{ Apr.-June } & \multirow{2}{*}{ July-Sep. } & \multirow{2}{*}{ Oct. - Dec } \\
\hline & & & Mean & Min. & Max. & & & \\
\hline 22 Apr.-10 May, 1993 & Off Saroma Lake & 179 & 213 & 123 & 372 & 9 & 1 & 0 \\
\hline 21 Apr.-12 May, 1994 & Off Saroma Lake & 199 & 202 & 140 & 329 & 30 & 0 & 0 \\
\hline 2 Dec. 1994 & Abashiri Bay & 366 & 259 & 207 & 330 & 29 & 3 & 1 \\
\hline 6 Nov. 1995 & Abashiri Bay & 267 & 278 & 200 & 374 & 2 & 0 & 8 \\
\hline
\end{tabular}
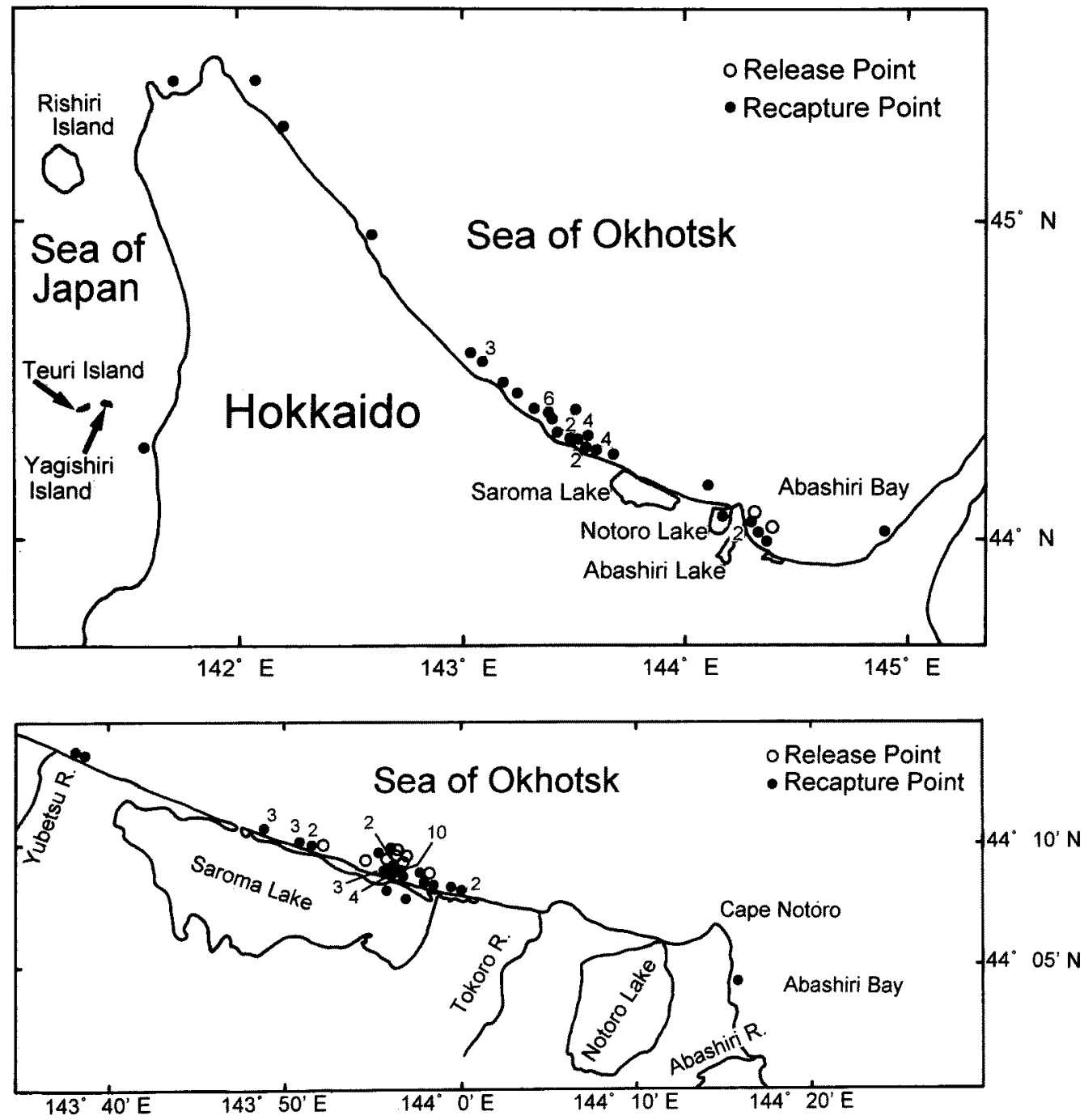

Fig. 4. Locations where tagged cresthead flounders were released from the Sea of Okhotsk off Saroma Lake between April and May in each of 1993 and 1994 (upper) and, from Abashiri Bay in 2 December 1994 and 6 November 1995 (lower), and corresponding recapture points.

Numerals with circles show the number of recaptures of more than two individuals.

(Ubaranai, Saroma T, and Saroma Y) and a sea group (Abashiri, Tokoro, Yubetsu, Monbetsu, Esashi, Rumoi, and Aonae). From a previous study, ${ }^{1}$ it has been thought that four stocks are distributed in these areas. It is difficult to consider independency of the Notoro Lake stock because some fishes released from Saroma Lake and the Sea of Okhotsk off Saroma Lake were recaptured in Notoro Lake. ${ }^{2)}$ A result of canonical discriminant analysis using morphometric characters shows that there is substantial overlap among lake samples (Fig. 3). Therefore, it may not be possible to separate stocks of cresthead flounders from
Notoro Lake and Saroma Lake.

Although the cresthead flounders released from the Sea of Okhotsk off Saroma Lake between June and August are recaptured in extensive regions from the Okhotsk Sea coast to the Japan Sea coast, ${ }^{2)}$ the fish released from the same area between April and May hardly move (Fig. 4). In Saroma Lake and Notoro Lake cresthead flounders spawn between April and May, ${ }^{11)}$ and during this period large amounts of matured fish are caught by flatfish gillnets in the Sea of Okhotsk off Saroma Lake. Accordingly, this group would be probably a lake group, and might live 
their whole lives in Saroma Lake and Notoro Lake and the vicinity of these along the Okhotsk Sea coast of Hokkaido. However, Tokoro and Yubetsu samples between June and October belong to a sea group (Fig. 3). This result suggests that the lake group concentrates in the Sea of Okhotsk off Saroma Lake only for the spawning period.

Yokoyama and Shimoyama ${ }^{2)}$ reported that a fish released from the Sea of Okhotsk off Saroma Lake was recaptured in the southern region from Shakotan peninsula. There is no separation of the Aonae sample and the other sea samples in the canonical discriminant analysis (Fig. 3). Thus, these facts suggest that the Shakotan stock and northern Japan Sea-Okhotsk Sea stock constitute the same morphological group.

Morphometric variation is known to be influenced by both environmental and genetic factors. The lake group grows more slowly* and has a larger head than the sea group (Table 4). Guénette et al. ${ }^{12)}$ reported that a sturgeon Acipenser fulvescens group grew slowly and had a relatively larger head, and the variation in the relative proportions of the head among sturgeon groups could be affected by environmental variation altering the growth rate. It is also confirmed in $\operatorname{cod}^{13)}$ and some salmonid juveniles ${ }^{14,15)}$ that morphometric variations in the head are affected by environmental conditions during the first stage of development. Cresthead flounders in the Okhotsk Sea coast select spawning areas whether in Saroma Lake and Notoro Lake or those of the Japan Sea coast. ${ }^{1,2,9)}$ Cresthead flounder larvae produced in the Sea of Japan are transported to the Sea of Okhotsk by the Soya Current. ${ }^{1)}$ Therefore, the nursery area of these larvae overlaps partially with that of the larvae produced in Saroma Lake and Notoro Lake. Accordingly, it is necessary to examine in which stage of early development large variations occur between a sea group and a lake group.

Although consistent patterns among meristic, morphometric, and genetic analyses of stock structure are absent in marine fish that had extensive drift of eggs and larvae, ${ }^{8,13,16)}$ analyses of anadromous fish tend to show consistent patterns among them. ${ }^{17-20)}$ It is assumed that the two groups preserve morphometric and genetic variations, because of the homing tendency of adults to the natal area. Further verification of the variations of groups is needed for the genetic analysis of each spawning stock.

Acknowledgments I wish to thank Dr. K. Ishino of Hakodate Fisheries Experimental Station, Mr. M. Watanobe of Wakkanai Fisheries Experimental Station, Mr. N. Shimoyama of Kushiro-seibu Fisheries Extension Office, Mr. H. Imai, Mr. K. Azuma, and Mr. H. Sugawara of Abashiri-chubu Fisheries Extension Office, Mr. K. Kobayashi of Abashiri Fisheries Cooperative Association, Mr. H. Fujiwara of Tokoro Fisheries Cooperative Association, and Mr. T. Kawajiri of NishiAbashiri Fisheries Cooperative Association who participated in the collection of cresthead flounder. Mr. M. Torisawa and Mr. K. Kawamata of Abashiri Fisheries Experimental Station reviewed a draft of this manuscript and offered suggestions.

\section{References}

1) S. Morita and M. Ohara: Ecological studies of "Kurogashiragarei"
(Limanda schrenki (Schmidt)) of Hokkaido (II). Consideration on the population. Bull. Hokkaido Natl. Fish. Res. Inst., 30, 60-66 (1965).

2) S. Yokoyama and N. Shimoyama: Movements of tagged cresthead flounder Pleuronectes schrenki off northeastern Hokkaido, Japan. Sci. Rep. Hokkaido Fish. Exp. Stn., 47, 101-110 (1996).

3) P. E. Ihssen, H. E. Booke, J. M. Casselman, J. M. McGlade, N. R. Payne, and F. M. Utter: Stock identification: Materials and methods. Can. J. Fish. Aquat. Sci., 38, 1838-1855 (1981).

4) R. Ishida: Local variation in meristic characters of Limanda schrenki (Schmidt). Sci. Rep. Hokkaido Fish Hatchery, 3, 16-22 (1948).

5) S. Okubo: Investigation on the flounder (Limanda schrenki) VI On the growth rate of flounder, using the otolith in Lake Notoro. Sci. Rep. Hokkaido Fish Hatchery, 7, 163-182 (1952).

6) R. E. Strauss and C. E. Bond: Taxonomic methods: morphology, in "Methods for Fish Biology" (ed. by C. B. Schreck and P. B. Moyle), American fisheries society, Bethesda, 1990, pp. 109-140.

7) D. G. Copeman: Population differences in rainbow smelt, Osmerus mordax: Multivariate analysis of mensural and meristic data. $J$. Fish. Res. Board Can., 34, 1220-1229 (1977).

8) H. J. Meng and M. Stocker: An evaluation of morphometrics and meristics for stock separation of Pacific herring (Clupea harengus pallasi). Can. J. Fish. Aquat. Sci., 41, 414-422 (1984).

9) S. Morita, H. Matsuyama, and M. Yamamoto: Age and fishing conditions of cresthead flounder. Hokusuishi Geppo, 23, 14-19 (1966) (in Japanese).

10) T. Tarumi and A. Hayashi: Seto/B, Kyoritsu shuppan, Tokyo, 1993, p. 220.

11) T. Hikita: On the development of Limanda schrenki (Schmidt). Sci. Rep. Hokkaido Fish Hatchery, 7, 133-144 (1952).

12) S. Guenette, E. Rassart, and R. Fortin: Morphological differentiation of lake sturgeon (Acipenser fulvescens) from the St. Lawrence River and Lac des Deux Montagnes (Quebec, Canada). Can. J. Fish. Aquat. Sci., 49, 1959-1965 (1992).

13) P. Pepin and S. M. Carr: Morphological, meristic, and genetic analysis of stock structure in juvenile Atlantic cod (Gadus morhua) from the Newfoundland shelf. Can. J. Fish. Aquat. Sci., 50, 19241933 (1993).

14) D. P. Swain, B. E. Riddell, and C. B. Murray: Morphological differences between hatchery and wild populations of coho salmon (Oncorhynchus kisutch): environmental versus genetic origin. Can. J. Fish. Aquat. Sci., 48, 1783-1791 (1991).

15) I. A. Fleming, B. Jonsson, and M. R. Gross: Phenotypic divergence of sea-ranched, farmed, and wild salmon. Can. J. Fish. Aquat. Sci., 51, 2808-2824 (1994).

16) D. Roby, D. Lambert, and J. M. Sevigny: Morphometric and electrophoretic approaches to discrimination of capelin (Mallotus villosus) populations in the Estuary and Gulf of St. Lawrence. Can. J. Fish. Aquat. Sci., 48, 2040-2050 (1991).

17) H. Svedäng: Genetic basis of life-history variation of dwarf and normal Arctic charr, Salvelinus alpinus (L.), in Stora Roson, central Sweden. J. Fish Biol., 36, 917-932 (1990).

18) G. D. Melvin, M. J. Dadswell, and J. A. McKenzie: Usefulness of meristic and morphometric characters in discriminating populations of American shad (Alosa sapidissima) (Ostreichthyes: Clupeidae) inhabiting a Marine Environment. Can. J. Fish. Aquat. Sci. 49, 266-280 (1992).

19) J. A. Vuorinen, R. A. Bodaly, J. D. Reist, L. Bernatchez, and J. J. Dodson: Genetic and morphological differentiation between dwarf and normal size forms of lake whitefish (Coregonus clupeaformis) in Como Lake, Ontario. Can. J. Fish. Aquat. Sci., 50, 210-216 (1993).

20) J. V. Baumgartner: Phenotypic, genetic, and environmental integration of morphology in a stream population of the threespine stickleback, Gasterosteus aculeatus. Can. J. Fish. Aquat. Sci., 52, 13071317 (1995).

\footnotetext{
* S. Yokoyama: Cresthead flounder, in "Annual Report 1994", Abashiri Fish. Exp. Stn., Abashiri, 1996, pp. 6-10 (in Japanese).
} 